\title{
Saúde sexual e reprodutiva no cárcere: discussão sobre os desafios das mulheres privadas de liberdade
}

Sexual and reproductive health in prison: a discussion on the challenges of women deprived of their liberty

Salud sexual y reproductiva en prisión: debate sobre los retos de las mujeres privadas de libertad

Amanda Bertinetti Tres ${ }^{1 *}$, Amanda Duarte de Sena ${ }^{2}$, Daniele Araújo Caires ${ }^{3}$, lally Mariana Brito de Lima $^{4}$, Kariny Coelho ${ }^{5}$, Letícia Ervilha Rigo ${ }^{6}$, Luana Oliveira da Silva ${ }^{7}$, Raquel Castro Ribeiro ${ }^{8}$, Vanessa Balieiro dos Santos ${ }^{9}$, Eduarda Faria Abrahão Machado ${ }^{10}$.

\section{RESUMO}

Objetivo: Analisar os desafios da saúde sexual e reprodutiva enfrentados por mulheres privadas de liberdade no Brasil. Revisão bibliográfica: A Constituição Brasileira de 1988 garante a saúde como um direito de todos, e dever do Estado. Entretanto, em presídios femininos, não há acesso garantido aos serviços de saúde, sobretudo da saúde sexual e reprodutiva, como deveria ser. As presidiárias, muitas vezes, estão sujeitas a escassez de produtos de higiene e a péssimas condições sanitárias. Vivem em um ambiente deletério e de superlotação. Percebe-se também uma maior vulnerabilidade das presidiárias a contrair infecções sexualmente transmissíveis, além de, em casos de gestantes, a assistência pré-natal, ao parto e ao pós-parto, não ser ofertada com a qualidade e o número de consultas mínimas necessárias. Considerações finais: As mulheres privadas de liberdade não têm uma saúde sexual e reprodutiva de qualidade dentro das penitenciárias, enfrentando dificuldades como: a falta de condições a uma boa higiene, gestação e parto não assistidos de maneira adequada. $O$ descumprimento da lei, que deve garantir a saúde como um direito de todos, infelizmente parece não ser cumprida nesses ambientes.

Palavras-chave: Mulheres, Saúde sexual e reprodutiva, Prisões.

\footnotetext{
ABSTRACT

Objective: To analyze the sexual and reproductive health challenges faced by women deprived of their liberty. Bibliographic review: The 1988 Brazilian Constitution guarantees health as a right of all and duty of the State, however, in women's prisons there is no guaranteed access to health services, especially sexual and reproductive health, since inmates are subject to scarcity of hygiene products and poor sanitary conditions. Thus, within female prisons, for example, there is greater vulnerability of inmates to contract sexually transmitted infections, since there is overcrowding and the environment is deleterious. In addition, when

${ }^{1}$ Centro Universitário de Mineiros (UNIFIMES), Mineiros - GO. *E-mail: amandabertinetti26@hotmail.com

2 Universidade Nove de Julho, São Bernardo do Campo - SP.

${ }^{3}$ Instituto Metropolitano de Ensino Superior (IMES- Univaço), Ipatinga - MG.

${ }^{4}$ Faculdade Santo Agostinho de Itabuna (FASA ITB), Itauna - BA.

5 Universidade Nove de Julho, Mauá - SP.

${ }^{6}$ Faculdade de Educação e Cultura de Vilhena (UNESC), Vilhena - RO.

7 Universidade Federal do Mato Grosso, Sinop - MT.

8 Universidade Federal de Lavras (UFLA), Lavras - MG.

9 Universidade Brasil (UNIBRASIL), Fernandópolis - SP.

${ }^{10}$ Faculdade de Medicina de Jundiaí, Jundiaí - SP.
}

SUBMETIDO EM: 5/2021

ACEITO EM: 6/2021

PUBLICADO EM: 7/2021 
pregnant women, prenatal, childbirth, and postpartum care is not offered with quality. Final considerations: Women deprived of their liberty do not have quality sexual and reproductive health within the penitentiaries, facing difficulties, among them there is: the lack of conditions of good hygiene, pregnancy, and childbirth not properly assisted. Thus, in women's prisons there is the non-fulfillment of the law that guarantees health as a right of all.

Key words: Women, Sexual and reproductive health, Prisions.

\section{RESUMEN}

Objetivo: Analizar los retos de salud sexual y reproductiva a los que se enfrentan las mujeres privadas de libertad. Revisión bibliográfica: La Constitución brasileña de 1988 garantiza la salud como un derecho de todos y un deber del Estado, sin embargo, en las cárceles de mujeres no se garantiza el acceso a los servicios de salud, especialmente a la salud sexual y reproductiva, ya que las reclusas están sometidas a la escasez de productos de higiene y a las malas condiciones sanitarias. Así, en las cárceles de mujeres, por ejemplo, hay una mayor vulnerabilidad de las reclusas a contraer infecciones de transmisión sexual, ya que hay hacinamiento y el ambiente es nocivo. Además, en el caso de las mujeres embarazadas, la atención prenatal, del parto y del posparto no se ofrece con calidad. Consideraciones finales: Las mujeres privadas de libertad no cuentan con una salud sexual y reproductiva de calidad dentro de los centros penitenciarios, enfrentando dificultades, entre ellas: la falta de condiciones de buena higiene, el embarazo y el parto no asistidos adecuadamente. Así, en las cárceles de mujeres se incumple la ley que garantiza la salud como un derecho de todos.

Palabras clave: Mujeres, Salud sexual y reproductiva, Prisiones.

\section{INTRODUÇÃO}

Embora no ano de 2020 tenha ocorrido um decréscimo de 10\% na população prisional (678.506 pessoas) em relação ao ano de 2016 (722.120 pessoas), a ocupação das prisões no Brasil segue, em sua maioria, com ocupação superior para a qual foi planejada, o que implica em pior qualidade de vida e aumento nas demandas para essa população (BRASIL, 2020).

Dessa forma, os desafios encontrados pelo sistema prisional brasileiro são vários, e destaca-se a lotação das cadeias, a baixa abrangência dos programas de ressocialização, além da precariedade dos atendimentos a saúde que ocorrem em quantidade aquém da necessidade, ainda que esse atendimento seja garantido por lei a essa população (BATISTA M, et al., 2018).

Os números publicados pelo Departamento Penitenciário Nacional trazem características da população prisional no país sendo: metade dos detentos pardos (50\%), $21 \%$ jovens entre 18 e 24 anos, $27 \%$ não possuem filhos e $23 \%$ possuem apenas um filho. Quanto às características das mulheres, nota-se que a população prisional feminina é composta por $4,91 \%$ do número total de pessoas, sendo que $36 \%$ cumprem penas com prazo entre 4 a 8 anos, e a maior parte são condenadas por tráfico de drogas (58\%) (BRASIL, 2020). Neste contexto, o impacto gerado pela baixa oferta de serviços de saúde, tanto para um suporte social como para a própria melhoria das condições de saúde, torna-se evidente quando comparamos os índices de adoecimento por Infecções Sexualmente Transmissíveis (IST), de mulheres livres com o das privadas de liberdade, com suas repercussões físicas e psicossociais (YASUKO L, et al., 2018).

A população de mulheres privadas de liberdade é uma população mais vulnerável a contrair IST. Esse fato é decorrente do escasso conhecimento sobre saúde sexual, impressões errôneas e às condições presentes no cárcere, o que acabam influenciando esse grupo a terem comportamentos de risco. Analisando os resultados das amostras deste estudo supracitado, uma em cada cinco mulheres da Cadeia Pública Feminina de Boa Vista $(\mathrm{RO})$, a realizar o teste rápido para alguma IST, teve resultado positivo, o que confirma a alta prevalência dessas infecções neste ambiente (BENEDETTI MSG, et al., 2020). 
Assim, também quando se avalia a mulher privada de liberdade em acompanhamento da gestação, parto e pós-parto, percebe-se maior vulnerabilidade dessas mulheres. Tanto pelas condições ambientais precárias, associada às mudanças físicas e emocionais inerentes à gestação, como pelas violações de direitos que a privação de liberdade no Brasil apresenta (CHAVES LH e ARAÚJO ICA, 2020).

De acordo com a literatura, as diferenças entre mulheres livres e mulheres encarceradas são realmente muito significativas. Ao serem comparadas nesse estudo, as mulheres encarceradas apresentaram menor escolaridade, sendo que $87,5 \%$ relataram possuir menos de oito anos de estudo; $55,6 \%$ vivia sem companheiro antes do encarceramento; $88 \%$ já teve gestações anteriores e $43,4 \%$ tiveram pelo menos um caso de aborto. Além disso, houve prevalência de tabagismo e uso abusivo de álcool na gestação em mulheres encarceradas (YASUKO L, et al., 2018).

Como bem apresentado, esses dados evidenciam a vulnerabilidade dessas mulheres e, somado a isso, as precárias condições de vida nas prisões e o difícil acesso ao mínimo de saúde. Em especial no campo da maternidade, é evidente a frágil assistência ao pré-natal e o não cumprimento do mínimo necessário, como o uso de algemas no pós-parto e a imposição à presidiária de estar sem acompanhante durante o parto. Assim, ressalta-se que o acesso à saúde no cenário da prisão não segue os princípios da integralidade, resolutividade e humanização que regem a saúde pública brasileira (REIS CA e ZUCCO LP, 2019).

Com essa explanação, o objetivo do presente estudo foi de revisar artigos científicos brasileiros sobre essa temática e analisar os desafios encontrados para a promoção da saúde e prevenção de doenças e complicações relacionadas à saúde sexual e reprodutiva dessas mulheres privadas de liberdade no Brasil, trazendo uma reflexão atualizada acerca do contexto social em que estas mulheres se encontram inseridas.

\section{REVISÃO BIBLIOGRÁFICA}

\section{O direito à saúde para as mulheres no cárcere}

O direito à saúde para a população presidiária, também, está estabelecido em outras legislações, como na Lei de Execuções Penais (LEP) de 1984, e na Política Nacional de Atenção Integral à Saúde das Pessoas Privadas de Liberdade no Sistema Prisional (PNAISP). No entanto, quando se analisa a aplicação dessas garantias, o que se observa é a não prestação do direito à saúde para esta população, principalmente quando se fala dos direitos relativos à saúde sexual e reprodutiva das mulheres em privação de liberdade (REIS CA e ZUCCO LP, 2019).

O Plano Nacional de Saúde no Sistema Prisional Penitenciário (PNSSP), de 2014, foi estabelecido para garantir a aplicação dos serviços do SUS nos presídios, com uma equipe de saúde responsável por atender até 500 presidiários, sendo formada por um médico, um enfermeiro, um psicólogo, um odontólogo, um assistente de enfermagem e um auxiliar de consultório dentário (BATISTA M, et al., 2018).

Ademais, segundo a LEP, mulheres privadas de liberdade têm o direito de receber visitas e visitas íntimas, ao menos uma vez por mês, além do direito ao pré-natal. Na ocasião de uma gestação, há a possibilidade de ela ser transferida para alguma unidade prisional que seja assistida por uma equipe médica, que possa acompanhar o pré-natal (COSTA LHR, et al., 2016).

Segundo a literatura, é importante lembrar que a prevenção e a promoção da saúde devem ser consideradas como atividades prioritárias para a população carcerária feminina, como já é garantido pelo SUS. Questões de insalubridade e superlotação no ambiente prisional são considerados fatores de risco para doenças infectocontagiosas, especialmente para esse grupo (DIUANA V, et al., 2016).

Ao analisar a questão do encarceramento feminino, deve-se estar atento às especificidades relativas ao gênero feminino. A maioria das unidades prisionais são projetadas para homens, com estrutura física de banheiros inadequados para as mulheres, com distribuição precária de absorventes e roupas íntimas, além de regulamentos que não atendem as particularidades femininas. Essas questões acabam por agravar mais ainda as desigualdades de gênero existentes (BATISTA M, et al., 2018). 
As demandas femininas envolvem as questões gestacionais, cânceres que tem maior incidência na população feminina, prevenção de violência, adoção de normas a despeito das questões de gênero, raça, etnia, orientação sexual, deficiência física e adaptações nas estruturas físicas das unidades prisionais (ANGOTTI B e SALLA F, 2018).

\section{Contexto histórico e social das mulheres no cárcere}

No Brasil, a questão do crime feminino ainda não foi totalmente explorada, visto que os autores que trabalham com o assunto não distinguem entre crimes masculinos e femininos. Esta visão é apoiada pela participação menor das mulheres no mundo do crime e pelo fato da população carcerária feminina representar apenas $6 \%$ do número total de prisioneiros no país. Em primeiro lugar, é realizado pesquisas com homens e, em seguida, é decidido o que deve ser criado, desenvolvido e implementado para as mulheres, especialmente para aquelas da classe social mais baixa, que geralmente têm diferenças de padrões, experiência e até habilidades intelectuais (FRANÇA MHO, 2014).

O estabelecimento e instalação de presídios femininos brasileiros ocorreram apenas no início da década de 1940 no Rio Grande do Sul, no Rio de Janeiro e em São Paulo. No entanto, especialmente após os anos 2000, houve mais estudos multidimensionais sobre o encarceramento feminino. Portanto, o número de obras em que mulheres brasileiras foram presas do ponto de vista histórico ainda pode ser considerado muito baixo (ANGOTTI B e SALLA F, 2018).

A literatura mostra que pesquisas sobre o crime feminino são mais difíceis do que o masculino, visto que elas cometem menos crimes e, assim, o número de presas é menor, implicando em maiores dificuldades para o estudo. No contexto do cárcere feminino, é observado que a punição está intimamente relacionada às questões de gênero, ou seja, algumas punições são direcionadas especificamente às mulheres (FRANÇA $\mathrm{MHO}, 2014)$.

Os serviços penais foram formulados para o público masculino, e posteriormente adaptados à tutela das mulheres, de forma que não pudessem cumprir as especificidades dos espaços e serviços que thes eram prestados. Além dos locais adequados, incluem também a amamentação em estabelecimentos prisionais e espaços infantis para custódia de gestantes, entre outras peculiaridades (DIUANA V, et al., 2017).

A fraqueza do sistema prisional brasileiro articula-se à permanência de uma cultura jurídica conservadora e desumana, que, através da violência, oprime e exime os indivíduos de condições ressocializadoras. Segundo dados do Levantamento Nacional de Informações Penitenciárias, realizado pelo Departamento Penitenciário Nacional, em 2014, a população carcerária no Brasil era de 607.731 para uma ocupação máxima de 376.669 penitenciários, o que reflete a superpopulação crescente do sistema carcerário do país. De acordo com o Informe 2014/15 da Anistia Internacional sobre o Estado dos Direitos Humanos no Mundo, especificamente acerca do sistema prisional brasileiro, as condições são degradantes e violam os direitos fundamentais, uma vez que essas garantias inexistem para as mulheres no cárcere (SANTOS APB e RIBEIRO LR, 2018).

Além do abandono do Estado no que diz respeito à infraestrutura dos presídios, as mulheres têm um fator psíquico social mais agravante que os homens, elas se distanciam das famílias, se separam dos filhos e, quando possuem companheiros, eles não as visitam mais. Sem perspectivas futuras e vivendo em um sistema prisional que não se preocupa com a ressocialização das detentas, essas mulheres ficam à margem e quando libertas não trilham um caminho diferente daquele que as levaram ao cárcere (SANTOS JBL e SILVA MS, 2019).

Uma das razões mais comuns para o envolvimento das mulheres no crime é a necessidade de complementar a renda familiar e o envolvimento emocional com seus parceiros. A maioria da população carcerária feminina é composta por mulheres negras, com baixa escolaridade e sem qualificação profissional. Portanto, para muitas pessoas, outra opção para aumentar sua renda é o tráfico de drogas. Para os criminosos, é divertido ter mulheres transportando drogas porque elas raramente atraem a atenção da polícia. Ao reduzir esses empregos na escala do tráfico, muitas pessoas acabam na prisão. Outros crimes comuns 
cometidos por presidiários incluem crimes conjuntos com seus parceiros e trazer drogas para a prisão, bem como seus maridos (DIUANA V, et al., 2017).

\section{Infecções sexualmente transmissíveis no cárcere}

Os primeiros casos de AIDS nos presídios ocorreram nos Estados Unidos no início da década de 1980, esses registros, se encontravam principalmente nas cidades de Nova York e Nova Jersey. De acordo com dados levantados pela InfoPen Estatística, o Brasil possui a quarta maior população feminina encarcerada do mundo (BRASIL, 2018).

Além disso, estudos recentes indicam alta prevalência de ISTs como o Vírus da Imunodeficiência Humana (HIV) $(0,0 \%$ a $26 \%)$, Sífilis $(2,2 \%$ a $22,8 \%)$ e Hepatite B $(3,8 \%$ a $26,4 \%)$ entre essas mulheres, ainda que fatores relacionados ao risco de transmissão não sejam claros na literatura, em grande parte, pois estudos sobre epidemiologia de ISTs entre a população brasileira privada de liberdade ainda são escassos (SOLEDADE M, et al., 2020).

Segundo Trigueiro DRSG, et al. (2016), o encarceramento pode influenciar não apenas na saúde física das detentas, mas também em seu aspecto psicológico, devido às mesmas se encontrarem em condição de isolamento e, muitas vezes, expostas a situações de violência e abuso sexual, responsáveis, também, pela transmissão de ISTs nesse ambiente. Além disso, a falta de educação em saúde contribui para o não conhecimento das detentas sobre a higiene, cuidados e necessidades do corpo feminino, bem como facilita a disseminação de informações errôneas e preconceituosas no contexto da saúde sexual feminina.

$\mathrm{Na}$ revisão de literatura que foi a base para a presente investigação, observou-se que as pessoas que se encontram privadas de liberdade compõem um dos grupos mais vulneráveis a contrair ISTs, haja vista que vivem em ambiente precário que induz a limitação de espaço. Dentre os principais fatores de risco, estão: ter mais de trinta anos, baixa escolaridade, pouco conhecimento sobre 0 uso de preservativos e 0 desconhecimento dos riscos e das formas de contágio dessas doenças que possuem alta incidência no ambiente carcerário (SOLEDADE M, et al., 2020).

Dados apurados na Cadeia Pública Feminina de Boa Vista (RO), indicam uma prevalência de $20 \%$ de ISTs entre as detentas, situação que está em conformidade com a realidade de outras prisões do país. Mesmo com alguns avanços da inclusão da população privada de liberdade em políticas públicas como a revisão do Plano Nacional de Saúde no Sistema Penitenciário (PNSSP) de 2010, a prática assistencial oferecida muitas vezes não está em conformidade com o previsto. Esse fator dificulta a prevenção e o diagnóstico precoce dessas doenças, comprometendo, assim, a realização de um bom tratamento e de uma evolução com bom prognóstico (BENEDETTI MSG, et al.,2020).

As ISTs podem envolver mais de trinta agentes etiológicos como vírus, fungos, bactérias entre outros, e apesar de serem comuns, possuem alta morbidade quando não precocemente diagnosticadas. Além disso, as consequências biológicas e psicossociais individuais e coletivas são graves, visto que podem reduzir a autoestima e a confiança das mulheres, bem como causar epidemias. Por isso, esse é considerado um problema grave de saúde que deve ser amplamente discutido com o fito de reduzir suas consequências (NICHIATA LYI, et al., 2019).

\section{Gestação e maternidade para mulheres no cárcere}

Entre as muitas questões que permeiam e servem de questionamento sobre a efetividade das leis criadas para garantir os direitos reprodutivos das mulheres no cárcere, está a gestação; que desde o início tende a ser desvalorizada e configura um reforço da prática penitenciária autoritária durante seu curso. O contexto de extrema vulnerabilidade e condições de vida insalubres, associado aos vínculos sociais fragilizados e abuso de drogas, faz com que mulheres que engravidaram antes de serem presas não tenham iniciado o pré-natal da maneira adequada (LOPES TC e PINHEIRO R, 2016).

Já inseridas no sistema prisional, esse cenário não tende a mudar, pelo contrário, elas ganham novos desafios no que diz respeito à tomada de decisões referente à gestação e ao parto. Em tese, existe uma equipe de saúde responsável pela assistência e as consultas até são agendadas, mas não necessariamente 
acontecem por conta da disponibilidade de horários, escassez de profissionais e demandas com critérios desconhecidos (VENTURA M, et al., 2015).

Em alguns casos, a gestante pode ser transferida para unidades prisionais mais próximas de serviços de saúde, para realização de pré-natal extramuro. Muitas relataram um intenso sofrimento durante essa logística, primeiro porque são afastadas das companheiras de cela com quem já estabeleceram algum vínculo, segundo porque sofrem no transporte e ao chegar às unidades de saúde. Algemadas e humilhadas, muitas relataram discriminação por parte da equipe e usuários do serviço de saúde (DIUANA V, et al., 2016).

A existência da Lei 8.080, de 19 de setembro de 1990, garante, dentro dos serviços do SUS, um acompanhante a todas as parturientes durante o trabalho de parto e pós-parto imediato. Entretanto, essa garantia parece não existir para mulheres prisioneiras, que desde o começo da gestação vivem a tensão e insegurança de passar pelo parto sozinhas, acorrentadas ou algemadas e por relato de algumas, "castigadas" (PINHEIRO R, 2016).

A maneira como os partos são conduzidos, com mulheres amarradas sob justificativa de custódia, como muitos agentes penitenciários defendem, não possui embasamento legal, visto que a Resolução CNPCP número 3, de 1 de junho de 2012, proíbe uso de algemas e qualquer outro meio de contenção antes, durante e no pós-parto imediato (VENTURA M, et al., 2015).

De acordo com o estudo de Reis CA e Zucco LP (2019), analisando o Presídio de Florianópolis e o alojamento "Materno-Fetal", as condições em que as mães e seus bebês permanecem abrigados são desprezíveis. Com base nos relatos colhidos durante a pesquisa, elas não recebem alimentação diferenciada, água filtrada, além do tempo de banho de sol inalterado quando comparado às outras detentas. Além disso, as normas internas não necessariamente são seguidas, posto que existe uma hierarquia dentro do Crime e algumas mulheres são negadas no alojamento por terem cometido práticas "não aceitas" pelas demais companheiras, que temem retaliações futuras. Sendo assim, as condições do alojamento podem ser piores para algumas, ficando confinadas em espaços ainda menores e sem acesso ao banho de sol durante todo 0 dia.

Em pesquisa feita no Centro de Referência à Gestante Privada de Liberdade (CRGPL) com dados de uma unidade Materno-Infantil de Minas Gerais, as detentas relataram ainda que as jornadas exaustivas de trabalho dentro da unidade não são reduzidas durante o período de resguardo e que essa rotina se estende ao bebê. Por não existir uma cuidadora e essas mulheres não terem autorização para se ausentar de suas funções na manutenção da unidade, são obrigadas a incluir os bebês em suas tarefas, submetendo-os a ambientes sujos e substâncias tóxicas (CHAVES LH e ARAÚJO ICA, 2020).

A função da mãe em relação ao bebê é pura e exclusivamente a amamentação, sendo ignorado qualquer laço afetivo por ela criado. Desse modo, o período em que são mantidos juntos se restringe aos primeiros 6 meses. Dados dessa pesquisa mostram que $54,10 \%$ das mulheres não sabiam com quem o(a) filho(a) ficaria após o período de amamentação, aumentando ainda mais a insegurança e o medo de que não exista um responsável legal pela criança fora da cadeia e esta passa a ser custodiada pelo Estado (CHAVES LH e ARAÚJO ICA, 2020).

\section{Aborto no cárcere}

Em um estudo descritivo com abordagem quantitativa realizado com 47 presidiárias do Piauí, acerca das condições socioeconômicas e sexuais, a frequência de abortos correspondeu a $72,3 \%$, sendo $42,5 \%$ desses ocorridos. O aborto por si só costuma ser resultante do pré-natal negligenciado, mas também consequência da falta de informação e suporte para as mulheres que se encontram gestantes e marginalizadas pelo próprio Estado, carecendo de suporte básico (BARROS MAR, et al., 2016).

A prática abortiva representa uma experiência traumática para a maior parte das mulheres que o realizam, segundo Queiroz MH e Martins NPB (2019), a maioria relata que a decisão de realizar o aborto não foi difícil, entretanto, após o procedimento sentiram-se culpadas e enfrentaram um período de instabilidade psicológica. Cabe ressaltar, ainda, que essas mulheres praticam o aborto em locais inapropriados e sem o suporte básico 
de atenção a sua saúde, o que pode implicar em complicações graves por conta da retenção de restos de placenta, seguida de infecção, peritonite, tétano e septicemia. Observa-se ainda, que o número de mulheres solteiras que abortam é maior do que as que possuem algum companheiro, uma vez que essas, não teriam a capacidade de educar e cuidar de seu filho caso o tivessem, devido às condições socioeconômicas em que se encontram.

Uma das grandes questões por trás das práticas abortivas dentro dos presídios, é o acesso restrito à anticoncepção. Mesmo as mulheres que mantinham o uso de algum método anticoncepcional antes do contexto prisional, quando privadas de liberdade, se veem desamparadas em relação ao cuidado com a contracepção, o que reforça, mesmo que de maneira indireta, a violação do direito à justiça reprodutiva. $\mathrm{Na}$ penitenciária, o acesso ao cuidado é limitado, a autonomia corporal é controlada e o movimento é restrito, em outras palavras, a noção de "escolha" reprodutiva é irrelevante (HAYES CM, et al., 2020).

O número de estudos e de projetos realizados voltados ao tema ainda são poucos uma vez que este ainda é considerado como um tabu pela sociedade, o que se mostra prejudicial devido à falta de informações sobre o assunto e a divulgação de crenças e informações falsas entre as mulheres e principalmente as detentas, que em sua maioria, não recebem as orientações adequadas ao passar por esse momento de tamanho impacto em sua vida (QUEIROZ MH e MARTINS NPB, 2019).

\section{CONSIDERAÇÕES FINAIS}

Por meio da análise desse estudo, pode-se inferir que apesar da existência de leis que garantam o acesso à saúde a população carcerária, esse serviço não é ofertado com a qualidade proposta. Percebe-se que o sistema prisional é despreparado para atender às necessidades da população feminina, que vive em um ambiente insalubre com superlotação, suscetível ao desenvolvimento de doenças infectocontagiosas, visto que essas mulheres não têm acesso adequado às políticas de promoção e prevenção de saúde. Além disso, é importante salientar que as gestantes privadas de liberdade recebem uma assistência pré-natal de má qualidade e têm seus direitos violados durante o parto e pós-parto. Por fim, conclui-se que os serviços de saúde sexual e reprodutiva oferecidos às mulheres privadas de liberdade são de baixa qualidade e carecem de atenção por parte das autoridades do Estado, para que seja oferecido um cuidado digno e humanizado, como previsto por lei.

\section{REFERÊNCIAS}

1. ANGOTTI B, SALLA F. Apontamentos para uma história dos presídios de mulheres no Brasil. Revista de História de las Prisiones, 2018; 6.

2. BARROS MAR, et al. Situação socioeconômica e reprodutiva de mulheres presidiárias. Revista de Pesquisa: Cuidado é Fundamental Online, 2016; 8(4): 4980-4985.

3. BATISTA M, et al. Direito à saúde para mulheres privadas de liberdade. Revista Jurídica, 2018; 53: 1-18.

4. BENEDETTI MSG, et al. Infecções sexualmente transmissíveis em mulheres privadas de liberdade em Roraima. Revista de Saúde Pública, 2020; 54(105): 1-7.

5. BRASIL. Departamento Penitenciário Nacional. Levantamento de dados prisionais - SISDEPEN. Ministerio da Justiça, 2020. Disponível em: https://www.gov.br/depen/pt-br/sisdepen

6. BRASIL. Levantamento Nacional de Informações Penitenciárias Infopen Mulheres, Ministério da Justiça, 2018. Disponível em: http://bvsms.saude.gov.br/bvs/publicacoes/cartilha_pnssp.pdf

7. CHAVES LH, ARAÚJO ICA. Gestação e maternidade em cárcere: cuidados de saúde a partir do olhar das mulheres presas em uma unidade materno-infantil. Revista de Saúde Coletiva, 2020; 3: 1-22.

8. COSTA, LHR, et al. Gênero no contexto dos direitos sexuais e reprodutivos de mulheres privadas de liberdade. Enfermería Global, 2016; 15(3): 138-175.

9. DIUANA V, et al. Direitos reprodutivos das mulheres no sistema penitenciário: tensões e desafios na transformação da realidade. Ciência \& Saúde Coletiva, 2016; 21: 2041-2050.

10. DIUANA V, et al. Mulheres nas prisões brasileiras: tensões entre a ordem disciplinar punitiva e as prescrições da maternidade. Physis: Revista de Saúde Coletiva, 2017; 27: 727-747.

11. DOMINGUES RMSM, et al. Prevalência de sífilis e HIV em gestantes encarceradas e incidência de sífilis congênita em crianças nascidas em prisões brasileiras. Cadernos de Saúde Pública, 2017; 33(11): 4-5.

12. FRANÇA MHO. Criminalidade e prisão feminina: uma análise da questão de gênero. Revista Ártemis, 2014; 18(1). 
13. HAYES CM, et al. "Reproductive Justice Disrupted: Mass Incarceration as a Driver of Reproductive Oppression", American Journal of Public Health, 110, S21-S24.

14. LOPES TC, PINHEIRO R. Trajetórias de mulheres privadas de liberdade: práticas de cuidado no reconhecimento do direito à saúde no Centro de Referência de Gestantes de Minas Gerais. Physis, 2016; 26(4): 1193-1212.

15. NICHIATA LYI, et al. Prevalência de infecções sexualmente transmissíveis em mulheres privadas de liberdade. Revista Saúde (Sta. Maria), 2019; 45(1).

16. QUEIROZ MH, MARTINS NPB. Como o número de abortos causados pela insalubridade carcerária contribui para uma dupla punição. Monogênesis, p 73.

17. REIS CA, ZUCCO LP. Saúde sexual e saúde reprodutiva no cárcere: Uma discussão necessária para garantia de direitos das mulheres privadas de liberdade. Revista Catarinense de História, 2019; 13: 83-84.

18. SANTOS APB, RIBEIRO LR. Prisão, família e serviço social: um recorte da realidade do centro de reeducação feminino Maria Júlia Maranhão. Anais do XVI Encontro Nacional de Pesquisadores em Serviço Social, 2018; 16(1).

19. SANTOS JBL, SILVA MS. Encarceramento feminino: reflexões acerca do abandono afetivo e fatores associados. Revista Psicologia Política, 2019; 19(46): 459-474.

20. SOLEDADE M, et al. Infecções Sexualmente Transmissíveis em mulheres privadas de liberdade em Roraima. Revista de Saúde Pública, 2020; 54: 105-116.

21. TRIGUEIRO DRSG, et al. AIDS and jail: social representations of women in freedom deprivation situations. Rev Esc Enferm USP. 2016; 50(4): 554-561.

22. VENTURA M, et al. Maternidade atrás das grades: em busca da cidadania e da saúde. Um estudo sobre a legislação brasileira. Cad. Saúde Pública, 2015; 31(3): 607-619.

23. YASUKO L, et al. Prevalência de infecções sexualmente transmissíveis em mulheres privadas de liberdade. Revista Saúde, 2018; 45: 1-10. 